\title{
Discussion on the Structure Hierarchy and States Differentiation of College Students Social Responsibility Identity
}

\author{
Min Chen
}

\author{
School of Marxism, Zhejiang University, Hangzhou, Zhejiang 310058, China
}

Keywords: College Students; Social Responsibility Identity; Structure Hierarchy; States Differentiation.

\begin{abstract}
The formation of social responsibility identity is the core purpose of college students responsibility education. From the perspective of psychological structure, college students social responsibility identity must undergo an imperceptible process from cognition to emotion then to practice. According to the initiative degree and identity consistency of college students' social life exploration, their social responsibility identity states can be divided into self-consciousness, dependency, diffusion and passive.
\end{abstract}

\section{Introduction}

The key point of moral education in colleges and universities is responsibility education, which has the core purpose of social responsibility identity formation. College students' identity of social responsibility is directly related to whether they can fulfill that on their own initiative and consciousness. Therefore, the research on college students' social responsibility identity can not only enrich the social identity theory, but also have important practical significance. Social responsibility refers to the responsibilities that certain social subjects assume and fulfill in order to build a better society as certain identities or roles, under certain conditions. According to the scope of subjects involved, it can be divided into the responsibility to oneself, to others, to the country and to the world [1]. Social responsibility identity of college students means, as the principal part, based on the understanding and cognition of social responsibility, their psychological acceptance and value choice will lead them to voluntarily accept the social responsibility which ought to be assumed; they will also transfer that into their own long-term stable intrinsic quality such as cognition, emotion, will and ability, and ultimately take it as a standard to guide their behavior and practice.

\section{Cognition, Emotion and Practice: Structure Hierarchy of College Students Social Responsibility Identity}

The essence of college students social responsibility identity is the independent choice of their view on responsibility, which is a complex spiritual and practical activity. Its realization needs to follow the general law of identity, and undergo an imperceptible process from cognition to emotion then to practice.

College students cognitive identity of social responsibility is to understand and grasp its basic connotation and elements, also to make positive evaluation on the premise of highly recognizing the social responsibility that they should undertake. On this basis, it will further manifest as the universal psychological tendency of inner acceptance and active practice. Realizing cognitive identity means to scientifically and accurately understand "what is social responsibility". According to historicity, concreteness and other characteristic of responsibility, clearly define the social responsibility of present college students, specifically refers to, in the practice of socialist core values, during the realization of Two Centenary Goals, in the great historic process of China Dream, college students should self-consciously perform the task, take up the mission, and bear the responsibility. Social responsibility emotional identity is sublimation to cognitive identity, a link between the preceding and the following in the identity process. It is a process of truly accepting the social responsibility that one should undertake, internalizing it into one's own responsibility system, forming positive emotional experience and then becoming a firm will and belief. It plays the role of regulation and control in the whole identity process, with the functions of motivating, inspiring and evaluating. Practice identity is the final stage and the highest level of social responsibility identity, which is in the core position. It requires college 
students to gradually integrate themselves into the social responsibility system in their life practice, and take it as their action standard and guide consciously, voluntarily and autonomously, so as to achieve the harmony between individuals and society.

College students social responsibility identity is not only a process of cognitive and emotional accordance and resonance, but also a course of behavioral convergence. This is a unified and integrated identity structure. Theoretically, the cognitive identity, emotional identity and practical identity of social responsibility are sequential and progressive, but from the perspective of practical process, it is difficult to distinguish their time sequence, which often shows co-advancement and mutual promotion.

\section{States and Related Differentiation of College Students Social Responsibility Identity}

Identity is a dynamic noun, which indicates one's value judgment and affiliation, and is also influenced by various environments and ideas. Its formation and strength always depend on the variations in increase and decrease of those elements [2]. Under the influence of objective factors such as interests, system and ideology, college students give their subjective initiative into full play and conduct social communication and practice through certain psychological and social mechanisms, forming different social responsibility identity states. The states of college students social responsibility identity is their status of social responsibility emotion, attitude and behavior, which reflects their identity degree of social responsibility and behavior way of expressing recognition.

\subsection{Different purposes of social participation promote different states of social responsibility identity}

The purpose of social participation can be examined from five aspects: cognition, obligation, conformity, benefit and value.

Cognition participation refers to that the main purpose of the subject is to learn and accumulate knowledge and skills.

Obligation participation is the social participation to fulfill the civic duty. This means that the subject exercises their rights and obligations of social participation in order to confirm their own identities.

Conformity participation means that the subject does not have a clear purpose of participation, but only follows the majority of people around or in the group, which is a kind of blind conformity.

Benefit participation refers to that the purpose of the subject is promoting or defending their own interests. In such condition, the participants will evaluate their expected benefits, and realization possibility of their benefits will determine the active degree of the participation, and whether the participation is stable or transient.

Value participation is the social participation that meets ideal belief needs of the subjects, that is, with certain value pursuit as the goal. This is the most stable, active and persistent social engagement.

The states of college students social responsibility identity is also affected by the purpose of their social participation, and since the participation efficiency and ways of various purposes are different, the states expressed and reflected are also different. Different purposes bring about different states. However, it should be pointed out that the purpose of college students social participation is not necessarily single. In many cases, it is a mixture of various purposes.

\subsection{Two abnormal states of college students social responsibility identity}

No matter whether college students realize the necessity of socialization or not, they have already been in the process of socialization. The difference is that they will actively participate, passively accept or escape. Because of various cognition and attitude, the forms of college students social responsibility identity are also different. Before making a detailed analysis of the states and characteristics of college students social responsibility identity, it is necessary to analyze two abnormal states.

Based on the fact that the author has been working on the ideological and political education of college students for a long time, nowadays there are two abnormal states in the overall situation of college students social responsibility identity. One is the social responsibility identity deficiency and the other is the excess. Both of these abnormal states are about problems of the social responsibility identity degree, which refers to it must conform to the certain requirements of political and economic development of society, be adapted to 
the social development stage as well as the development of social individuals. Social responsibility identity deficiency means that it does not meet the requirements of their age, role and social life, which reflected in social responsibility cognitive complanation, absolutization and one-sided, poor emotional control ability and anti-interference ability, weak willpower, bad adaptability to the environment, inferior roles coordination and behavior ability, overdependent on intimate relationships, excessive high expectations on others and the society, but low requirements for their own actions, hard to find the link between their own development and social needs. Social responsibility identity excess means that it exceeds the boundaries of their psychological, age and physical development, and there is a deviation of identity, which leads to the situation that is not conducive to their own development. They are too utilitarian during their social participation and maintenance of social relations. They show a positive attitude in the fulfillment of social responsibilities. However, their activities and goals are centered on the acquisition of personal benefits, and they always have a single orientation in understanding the relationship among individuals and others, the collective, country and society, as well as are narrow in thinking, cold in human relations and so on. Both of the above two abnormal states are not what we advocate, since they are neither conducive to the personal growth and development of college students, nor in line with social expectations for college students.

\subsection{Theoretical states differentiation of college students social responsibility identity}

According to the initiative degree and identity consistency of college students' social life exploration, from the perspective of value direction and value state performance, their social responsibility identity states can be theoretically divided into the following states:

Self-consciousness identity: this is a mature status of social responsibility identity. Under this condition, the college students will have comprehensive responsibility cognition and undertake their own social responsibility with full pride. In practice of the social life, they are willing to learn, to explore actively, and keeping keen interest. They have firm value orientation for their own responsibility behavior, can accept social leading values, and consciously unify the requirement of that and their own development, to form the belonging and trust sense to society, and actively participate in the social activities, fulfill their own commitments and responsibilities.

Dependency identity: this type of college students has certain explore consciousness and clear interests demand, identity subject needs to earn interests from the object, or to achieve interests with the help of the object [3]. In order to obtain some kind of external benefit or avoid disagreement with social norms and requirements to incur punishment, they may form obedience to the social responsibility. However, this kind of identity is driven by a direct short-term interest; it is weak and unstable, with conformity and utilitarian; it is easy to form as well as easier to change. It to a large extent can bring about a false or fake identity, that is to say, because of external pressure and situation, the subjects seem to assume the social responsibility, but in fact it is a kind of surrender, which does not conform to their inner value orientation, they may hold the opposite opinions in heart, eventually leading to the difference between the attitude and behavior.

Passive identity: also called "blind obedience". This type of college students lack the consciousness of social practice exploration, but on the basis of education, guidance and training, they can cooperate with and accept the requirements of social responsibility norms, can achieve the basic identity of social responsibility. This depends on the external influence strength or the degree and way of influence. It can be transformed to the self-consciousness identity by increasing influence strength and improving the influence approach.

Diffusion identity: also called "apathetic identity". This is a state of no clear responsibility consciousness, this type of college students has no willing to participate in social practice actively, don't think themselves having connection with social responsibility. There is no clear development needs. They tend to avoid social responsibility, even if there is any support for the social requirements, the behavior is passive. This kind of identity is cold, alienated and wavering, and contains the possibility of responsibility relaxing or confrontation.

Based on the above analysis, if the degree of college students social responsibility identity is taken as the horizontal coordinate and the degree of their active exploration in social communication and life is taken as the vertical coordinate, the following figure can be used to represent the four states of college students social responsibility identity. 
Active Exploration

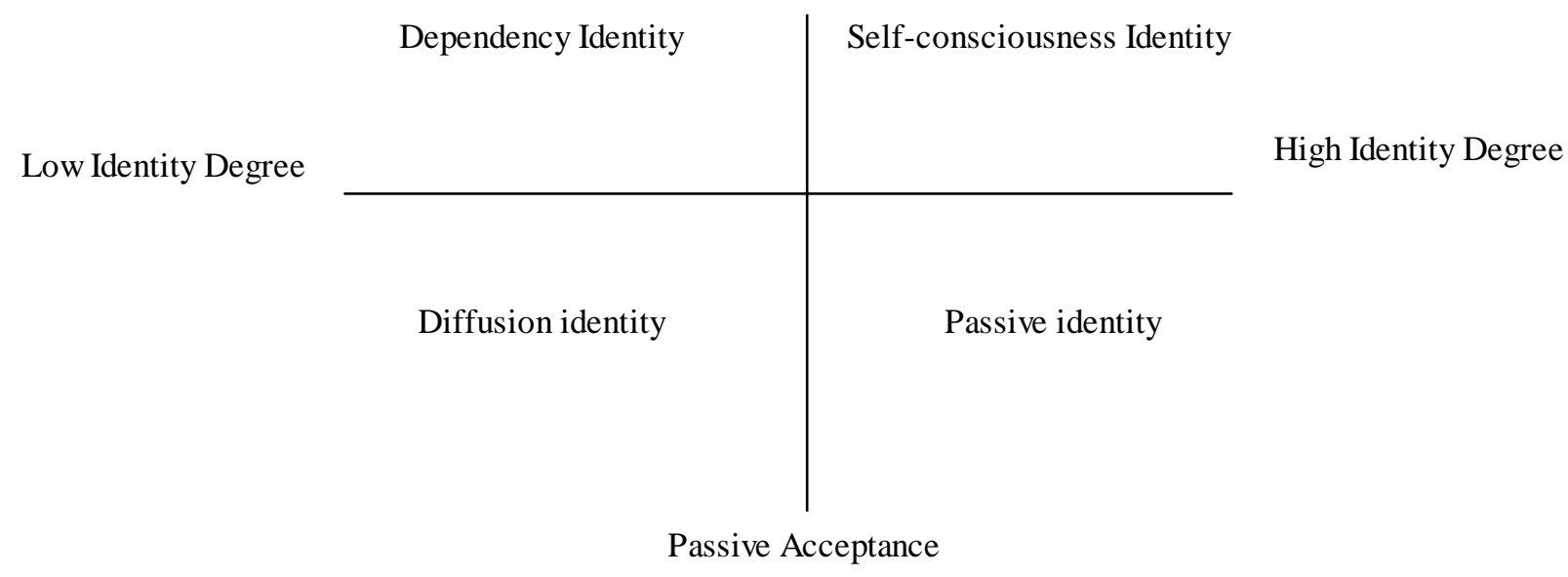

Fig. 1 Theoretical States Differentiation of College Students Social Responsibility Identity

Since the restriction of consciousness and practice, different social responsibility identity subject will show some difference between each other because of their different positions, various goals and contents of the interests in the group or organization, but it should be stressed that, the four states above, in order to analyze easily, just summarized the basic states of college students social responsibility identity. In fact, the manifestation of social responsibility identity could be more complicated. Different states also have the possibility of mutual transformation. Absolutely stable and permanent states of social responsibility identity cannot exist.

\section{Conclusion}

College students social responsibility identity has rich connotation, as well as the inherent logic and characteristics generated by itself. It is the premise and foundation to carry out the responsibility education for college students to grasp the structural hierarchy and the states differentiation characteristics of college students social responsibility identity. In the process of implementing the responsibility education for college students, we must fully understand the above-mentioned connotation and features, give full play to the subjectivity of college students, and realize their high identity of social responsibility, to promote their realization of life value in vivid social practice.

\section{References}

[1]. Jianqing Ma, Zengyan Chen, "An analysis of Xi's important discourse on the social responsibility of youth,” Studies on Mao Zedong and Deng Xiaoping Theories, pp. 18, 2016(10).

[2]. Ruoheng Li, Jie Chen, "The national identity and political identity of "post-90s" college students from the perspective of Consumerism,” Research of Modern Young People, pp.42, 2013(2).

[3]. Jun Dai, "Research on political identity in contemporary China's transitional society -- from the perspective of value analysis,” Doctoral Dissertation, Shaanxi Normal University, Nov 2010. 